Meta

Journal des tradlucteurs

Translators' Journal

\title{
À propos de régimes de retraite
}

\section{Service de linguistique du Canadien Pacifique}

Volume 16, numéro 3, septembre 1971

URI : https://id.erudit.org/iderudit/003934ar

DOI : https://doi.org/10.7202/003934ar

Aller au sommaire du numéro

Éditeur(s)

Les Presses de l'Université de Montréal

ISSN

0026-0452 (imprimé)

1492-1421 (numérique)

Découvrir la revue

Citer cet article

Service de linguistique du Canadien Pacifique (1971). À propos de régimes de retraite. Meta, 16(3), 174-175. https://doi.org/10.7202/003934ar d'utilisation que vous pouvez consulter en ligne.

https://apropos.erudit.org/fr/usagers/politique-dutilisation/ 


\section{À PROPOS DE RÉGIMES DE RETRAITE}

\section{Contributory Earnings - Salaire cotisable}

Le salaire cotisable est la tranche du salaire sur laquelle sont perçues des cotisations. «Cotisable » est un néologisme, mais un néologisme fort utile et dont la formation respecte les structures de la langue française.

\section{Early/Normal Retirement}

L'expression early retirement désigne une retraite qui est prise avant la date prévue; il s'agit donc d'une retraite anticipée (Petit Robert) et non d'une retraite

3. Dictionnaire des métiers et appellations d'emploi, établi par la Commission interministérielle de la nomenclature des métiers, Institut national de la statistique et des études économiques, Presses Universitaires de France, Paris, 1955, p. 131. 
prématurée qui serait une retraite prise trop tôt du point de vue de l'employeur ou de l'employé.

L'expression retraite à l'âge normal est de beaucoup préférable à « retraite normale »; car, que serait une retraite anormale ? L'âge normal est l'âge conforme à la norme, l'âge habituel où l'on prend sa retraite.

\section{Proof of Age - Justification d'âge}

Justification d'âge semble le terme le plus exact car « justification » désigne une pièce qui sert à justifier ou à prouver (Petit Larousse). Mais peut-on justifier de son âge? Pourquoi pas, puisque le Petit Robert consigne « justifier de son identité en montrant ses papiers $\gg$.

Service de linguistrque du Canadien Pacifique 